\title{
Assessing the mental health condition of home-confined university level students of Bangladesh due to the COVID-19 pandemic
}

\author{
Muhammad Khairul Alam ${ }^{1}$ (D) Ferdous Bin $\mathrm{Ali}^{1} \cdot$ Rajon Banik $^{2} \cdot$ Sabina Yasmin ${ }^{1} \cdot$ Nahid Salma $^{1}$ \\ Received: 10 September 2020 / Accepted: 3 April 2021 / Published online: 17 April 2021 \\ (C) The Author(s), under exclusive licence to Springer-Verlag GmbH Germany, part of Springer Nature 2021
}

\begin{abstract}
Aim The COVID-19 pandemic drove the Government of Bangladesh to shut down educational institutions, which had an enormous effect on the psychological health of students. This study aimed to assess the mental health status of Bangladeshi university students during the lockdown period.

Subject and methods Through an online-based questionnaire, information was collected from 509 university students of Bangladesh from June 19, 2020, to June 28, 2020, using convenient sampling. K-means clustering was applied to organize students according to their psychological health score, and confirmatory factor analysis (CFA) was also conducted to determine the association among the student's activities and their mental health during the pandemic. In addition, these associations were examined through chi-square test and ordinal logistic regression.

Results Students were categorized into four categories where $4.32 \%$ had mild, $72.7 \%$ had moderate, $12.57 \%$ had moderately severe, and $10.41 \%$ suffered from severe mental health imbalance. The results showed that having family members affected by the coronavirus, facing insecurity, using social media, and smoking habits increased the mental health imbalances of students; in contrast, being worried about studying, future career, spending more time with family members, and participation in household chores reduced the mental health disturbances of students. On the other hand, the results of the ordinal logistic regression indicated that sleeping time and participation in household chores were preventive factors for students.

Conclusion This study reveals that a large proportion of University students of Bangladesh suffered from mental health disturbances during the lockdown period. Implementing mental health plans and providing job security, improved communication approaches toward family members, not flattening illusive news, and preoccupation in household activities may assist to enhance the mental health status of the university students. The authors believe that this study's findings will be helpful to expedite the rate of attaining the sustainable development goal associated with health status in Bangladesh.
\end{abstract}

Keywords COVID-19 $\cdot$ Lockdown $\cdot$ University students $\cdot$ Mental health assessment

\section{Introduction}

The coronavirus disease 2019 (COVID-19) pandemic caused by the novel coronavirus (2019-nCoV) originated in Wuhan, Hubei province, China at the end of 2019, and has gained intense attention globally (Wang et al. 2020a; Xiang et al. 2020). The World Health Organization (WHO) revealed the

Muhammad Khairul Alam

alamstat228@gmail.com

1 Department of Statistics, Jahangirnagar University, Savar, Dhaka 1342, Bangladesh

2 Department of Public Health and Informatics, Jahangirnagar University, Savar, Dhaka 1342, Bangladesh appearance of the novel coronavirus (2019-nCoV) on January 30, 2020, as a public health emergency of international concern (PHEIC) (World Health Organization 2020a). The pandemic has been threatening human welfare globally, including in Bangladesh. COVID-19 was officially introduced in Bangladesh on March 8, 2020 (Banik et al. 2020), and since then, approximately 68,504 cases of COVID-19 were recorded and inveterate with at least 930 deaths as of June 08, 2020 (Institute of Epidemiology Disease Control and Research 2020). The COVID-19 pandemic impacts not only on substantial strength but also the mental health of the public due to being in quarantine for a long time during this ongoing global concern (Brooks et al. 2020; Wang et al. 2020b). Uncertainty and unpredictability concerning such pandemics ranging from epidemiological features, rapid transmission 
patterns, novelty, and severity of public health have effects in an extensive range of psychosocial aspects and mental catastrophes such as depression, anxiety, and traumatic stress (Xiao 2020; Zandifar and Badrfam 2020).

To deal with these pandemic social distancing measures such as quarantine, lockdown is most effective (Anderson et al. 2020; Brooks et al. 2020). Similar to many affected countries, the Government of Bangladesh has also declared the closing of all educational institutions, including schools, colleges, and universities since March 18, 2020, to restrict public gathering and encourage staying home (The Daily star 2020). As a result, students' regular lifestyles were disturbed and this long lockdown period psychologically affects people, including through increased media reporting about an invasion of the latest transmissions (Rubin and Wessely 2020). Evidence from another study showed that people in the quarantine may suffer psychological distress mostly in the form of anxiety, anger, frustration, and symptoms of post-traumatic stress (Brooks et al. 2020).

Owing to this pandemic situation, students have spent a longer time at home than usual and that may have an adverse effect on their mental health, which not only harms specific students but also has substantial negative impacts on society (Goothy et al. 2020). Because there is a certain age limit (30 years) of students to obtain a government job in Bangladesh, this unexpected delay to complete their final degree makes them upset as well as depressed (Lipi 2020). Additionally, it is difficult to be confined in the home for a young person within the age range 19-28 years, which may lead to cabin fever that refers to the distressing claustrophobic irritability or restlessness experienced when a person, or group, is stuck at an isolated location or in confined quarters for an extended time. Moreover, the students who just started their university journey (first year) have done very few classes and therefore become impatient day by day. Importantly, many students plan to pursue higher education abroad each year, but due to this worldwide emergency, they had to cancel their plans. All these factors will lead to feeling psychological insecurity.

Therefore, it is necessary to assess the mental health condition among university level students as well as to identify the factors that affect their psychological health while quarantined at home as an extensive lockdown due to COVID-19. This study endeavors to investigate the psychological health challenges faced by Bangladeshi university students during this COVID-19 pandemic.

\section{Methods}

\section{Study population and sample}

To assess the mental health condition during the COVID-19 pandemic, this cross-sectional study was conducted among the university students of Bangladesh from June 19, 2020, to
June 28,2020 , through an online survey. Owing to health concerns, face-to-face interviews were avoided. The data was collected via an online questionnaire (Google Form) from students after 110 days of home-quarantine following lockdown declared by the Government on March 25, 2020 (World Health Organization 2020b). The respondents in the target population were sampled following the convenient sampling strategy. The questionnaires were unidentified to guarantee the secrecy and consistency of data. Formal consent was obtained from each respondent before completing the questionnaire. The online form was shared with students through social media (Facebook, WhatsApp, and Instagram). Being a student of any university in Bangladesh was the only eligible criterion. A total number of 509 respondents completed the questionnaires and were included in the final analysis.

\section{Data collection procedure}

The questionnaire consists of four sections: (i) basic information of students (age, gender, current living place, type of university, studying year, and living status), (ii) student's information related to COVID-19, (iii) activities during the lockdown period, and (vi) mental health assessment questionnaire.

\section{Mental health assessment}

Student's depression was assessed by the 9-item Patient Health Questionnaire (PHQ-9) (Kroenke et al. 2001). (i.e., little interest or pleasure, feeling down, depressed or hopeless, difficulty falling or staying slumbering, feeling tired or having little energy, poor appetite or overeating, feeling terrible about yourself or your family down, trouble concentrating on reading the newspaper or watching television, moving or speaking slowly, better off dead or of hurting yourself). The score of each scale is measured by a 4-point scale $(0=$ not at all, $1=$ several days, $2=$ more than half the days, and $3=$ nearly every day), where total scores were represented as $0-5=$ mild, $6-$ $10=$ moderate, $11-15=$ moderately severe, and $16-20=$ severe depression.

Generalized anxiety disorder (GAD-7) was used to evaluate the anxiety of students. The GAD is a 7-item questionnaire (i.e., feeling nervous, anxious or on edge, not being able to stop or control worrying, worrying too much about different things, trouble relaxing, being so restless that it is hard to sit still, becoming easily annoyed or irritable and feeling afraid as if something awful might happen) (Budikayanti et al. 2019). The occurrence of each scale is judged by a 4-point scale $(0=$ not at all, $1=$ several days, $2=$ more than half the days, $3=$ nearly every day), and overall scores were represented as 0 $5=$ mild, $6-10=$ moderate, $11-15=$ moderately severe anxiety, and $15-21=$ severe anxiety. 
A more accurate measure of individual stress is the Perceived Stress Scale (PSS). It measures the degree of stress to a particular situation in one's life (Cohen et al. 1994). The PSS score can be determined by first overturn scores for questions $4,5,7$, and 8 . For these four questions, the changes score as $0=4,1=3,2=2,3=1$, and $4=0$. For each question, the 4 point scale is $0=$ never, $1=$ rarely, $2=$ sometimes, $3=$ fairly often, and $4=$ very often. The object scores on the PSS can range from 0 to 40 with higher scores representing the top level of stress. The overall scores were represented as $0-13$ : low stress, 14-26: moderate stress, and 27-40: high perceived stress.

\section{Data analysis}

Descriptive statistics were conducted to exemplify the basic information of students and other selected characteristics. Kmeans clustering methods were applied to cluster the three scales PHQ-9, GAD-7, and PSS. The Euclidean distance was considered as a measurement scale. Students were partitioned into four categories by the Ward's method. Corresponding to the grouping, the mental health assessment of students was compared. The association test was applied to determine the relationship between clusters and different variables related to the characteristics of students.

The estimates of the strength of association were measured by Ordinal logistic regression analysis with $95 \%$ confidence interval. Confirmatory factor analysis (CFA) was constructed to explore the relationship among the four components, such as student information, thinking related to COVID-19, activities during a pandemic, and mental health (GAD-7, PHQ-9, PSS). In CFA, root mean squares (RMS) values are close to 0.06 and Tucker-Lewis index (TLI) values $>0.90$, which is considered as an indicator for a good fit of the proposed model. Finally, using the proposed cutoff criteria, the ML-based TLI, RMSEA is less preferable for small sample sizes $(<200)$ (Hu et al. 1999). Data analysis was conducted using IBM SPSS (Statistical package for social science) for Windows (Version 22.0) and SPSS AMOS (Version 25.0).

\section{Results}

The survey was conducted on a total number of 509 participants, where $358(70.3 \%)$ are from public and 151 (29.7\%) are form private university students of Bangladesh. Among them, $298(58.5 \%)$ students were male and $211(41.5 \%)$ female. In the sample population, $96.7 \%$ of students were aged between 18 to 28 , and $88.8 \%$ of students were living with their family members. Additionally, $74.3 \%$ students were living in an urban area, $99.2 \%$ of the students had awareness about COVID$19,65.8 \%$ of students faced insecurity and stress, and $79.9 \%$ of students felt uncomfortable thinking about COVID-19. The results are illustrated in Table 1.

By considering the GAD-7, PHQ-9, and PSS scores, 509 students were partitioned into four groups. Among them, $4.32 \%$ of students had mild mental health instabilities (average PSS 1.82, PHQ-9 1.91, GAD-7 1.73), 72.7\% of students had moderate instabilities (average PSS 2.46, PHQ-9 3.69, GAD-7 3.48), $12.57 \%$ of students had moderately severe instabilities (average PSS 2.48, PHQ-9 3.44, GAD-7 1.52), and $10.41 \%$ of students had severe instabilities (average PSS 2.23 , PHQ-9 1.45, GAD-7 3.51). There were significant differences between these three scales scores among the four groups. The results are shown in Table 2.

To find the significant differences in different characteristics among the four groups, the chi-square test was used. There were significant differences in the age of students; in the severe disturbance group, most of the students were 18-22 aged $25(47.20 \%)$. No other variable in the section "Basic information of students" was significantly different among these four groups. In contrast, there were no significant differences in the section "Information related to COVID-19" as shown in Table 3. However, significant differences were found in the duration of staying at home, worrying about their studies and future career, time to go to sleep and wake up from a bad dream. Students worried about their studies and future career $20(37.7 \%)$ and $19(20.30 \%)$, respectively. There was no significant difference among duration of staying at home, watching videos in social media, religious activities, and smoking more during this pandemic with mental health scores of students. Alternatively, the results showed that students spending more time on social media (22.60\%), not at all wake up from sleep from bad dreams (50.9\%), more interaction with family (26.4\%), participation in household chores (24.5\%), and feeling bored at staying home (30.20\%) were more likely to be severely depressed, anxious, and stressed. The results are shown in Table 3.

The results indicated that students worried about their studies, in respect to not worried about it, was a conservative factor against mental health assessment of students experienced by the students $(\mathrm{OR}=3.866,95 \% \mathrm{CI}=(-1.18,-.002))$, students activities on going to sleep were also protective factors against mental health assessment of students $((\mathrm{OR}=8.788,95 \%$ $\mathrm{CI}=(0.231,1.14)),(\mathrm{OR}=4.666,95 \% \mathrm{CI}=(0.115,2.39))$, $(\mathrm{OR}=1.376,95 \% \mathrm{CI}=(-2.68,0.52)))$, and participation in household chores $(\mathrm{OR}=8.405,95 \% \mathrm{CI}=(-1.48,-0.29))$. Results are shown in Table 4.

The proposed latent variables in CFA were student information included with age, living place, and living status. Thinking related to COVID-19 included knowledge about COVID-19, relatives were affected, and facing financial insecurity. Activities during the pandemic included bad dreams caused waking up, interaction with family members, and participation in household chores. Lastly, mental health 
Table 1 Demographic and COVID-19 related information of university level students

\begin{tabular}{|c|c|c|c|}
\hline Variables & Categories & $\begin{array}{l}\text { Frequency } \\
(n)\end{array}$ & $\begin{array}{l}\text { Percentage } \\
(\%)\end{array}$ \\
\hline \multirow[t]{4}{*}{ Age (in years) } & $18-22$ & 229 & 45 \\
\hline & $23-25$ & 198 & 38.9 \\
\hline & $26-28$ & 65 & 12.8 \\
\hline & More than 28 & 17 & 3.3 \\
\hline \multirow[t]{2}{*}{ Gender } & Male & 298 & 58.5 \\
\hline & Female & 211 & 41.5 \\
\hline \multirow[t]{2}{*}{ Current living place } & Urban & 378 & 74.3 \\
\hline & Rural & 131 & 25.7 \\
\hline \multirow[t]{2}{*}{ Type of university } & Public & 358 & 70.3 \\
\hline & Private & 151 & 29.7 \\
\hline \multirow[t]{6}{*}{ Studying year } & First year & 57 & 11.2 \\
\hline & Second year & 88 & 17.3 \\
\hline & Third year & 136 & 26.7 \\
\hline & Fourth year & 109 & 21.4 \\
\hline & Fifth year & 4 & 0.8 \\
\hline & Master's & 115 & 22.6 \\
\hline \multirow[t]{4}{*}{ Living status } & With family & 452 & 88.8 \\
\hline & Relatives home & 9 & 1.8 \\
\hline & Alone & 33 & 6.5 \\
\hline & Others & 15 & 2.9 \\
\hline \multirow[t]{4}{*}{ Knowledge about COVID-19 } & Good & 167 & 32.8 \\
\hline & Medium & 239 & 47.0 \\
\hline & Excellent & 99 & 19.4 \\
\hline & No knowledge & 4 & 0.8 \\
\hline \multirow[t]{2}{*}{ Views about COVID-19 } & Positive & 118 & 23.2 \\
\hline & Negative & 391 & 76.8 \\
\hline \multirow[t]{2}{*}{ Family member affected by COVID-19 } & Yes & 9 & 1.8 \\
\hline & No & 500 & 98.2 \\
\hline \multirow[t]{2}{*}{ Relatives or neighbors affected by COVID-19 } & Yes & 128 & 25.1 \\
\hline & No & 381 & 74.9 \\
\hline \multirow[t]{2}{*}{ Facing insecurity and stress } & Yes & 335 & 65.8 \\
\hline & No & 174 & 34.2 \\
\hline \multirow[t]{5}{*}{ Feel discomfort thinking about COVID-19 } & Strongly disagree & 19 & 3.7 \\
\hline & Disagree & 27 & 5.3 \\
\hline & Neither agree nor disagree & 57 & 11.2 \\
\hline & Agree & 223 & 43.8 \\
\hline & Strongly agree & 183 & 36 \\
\hline
\end{tabular}

assesment is made based on GAD-7, PHQ-9, and PSS scores of students. The chi-square test of the proposed model fits with a value of 82.69 , with a degree of freedom $48, p$ value 0.001 , TLI 0.924 , CFI 0.620 , and RMSEA 0.038 indicating
Table 2 Cluster analysis combination among three mental health scales (PSS, GAD-7, and PHQ-9)

\begin{tabular}{llllll}
\hline Variables & Mild $n(\%)$ & Moderate $n(\%)$ & Moderately severe $n(\%)$ & Severe $n(\%)$ & $p$ value \\
\hline Total & $22(4.32)$ & $370(72.7)$ & $64(12.57)$ & $53(10.41)$ & \\
PSS(SD) & $1.82(0.46)$ & $2.46(0.50)$ & $2.48(0.50)$ & $2.23(0.51)$ & 0.000 \\
GAD-7(SD) & $1.73(0.53)$ & $3.48(0.46)$ & $1.52(0.50)$ & $3.51(0.50)$ & 0.000 \\
PHQ-9(SD) & $1.91(0.73)$ & $3.69(0.55)$ & $3.44(0.50)$ & $1.45(0.69)$ & 0.000 \\
\hline
\end{tabular}


Table 3 Comparison of basic information and information related to COVID-19 with different clusters

\begin{tabular}{|c|c|c|c|c|c|c|c|}
\hline Factors & Categories & Mild $n(\%)$ & Moderate $n(\%)$ & $\begin{array}{l}\text { Moderately } \\
\text { severe } n(\%)\end{array}$ & $\begin{array}{l}\text { Severe } \\
n(\%)\end{array}$ & Total $n(\%)$ & $p$ value \\
\hline \multirow[t]{4}{*}{ Age } & $18-22$ & $6(27.30)$ & $179(48.40)$ & $19(29.70)$ & $25(47.20)$ & $229(45.0)$ & 0.026 \\
\hline & $23-25$ & $13(59.10)$ & $136(36.80)$ & $30(46.90)$ & $19(35.80)$ & 198(38.90) & \\
\hline & $26-28$ & $1(4.50)$ & $46(12.40)$ & $10(15.60)$ & $8(15.10)$ & $65(12.80)$ & \\
\hline & More than 28 & $2(9.10)$ & $9(2.40)$ & $5(7.80)$ & $1(1.90)$ & $17(3.30)$ & \\
\hline \multirow[t]{2}{*}{ Worried about studies } & No & $15(68.20)$ & $303(81.9)$ & $46(71.9)$ & $33(62.3)$ & $397(78.0)$ & 0.004 \\
\hline & Yes & $7(31.8)$ & $67(18.1)$ & $18(28.1)$ & $20(37.7)$ & $112(22.0)$ & \\
\hline \multirow[t]{2}{*}{ Worried about future career } & No & $13(59.1)$ & $316(85.4)$ & $51(79.7)$ & $34(64.2)$ & $414(81.3)$ & 0.000 \\
\hline & Yes & $9(40.9)$ & $54(14.6)$ & $13(20.3)$ & $19(20.3)$ & $95(18.7)$ & \\
\hline \multirow[t]{2}{*}{ Spending more time on social media } & No & $13(59.1)$ & $316(85.4)$ & $51(79.7)$ & $41(77.4)$ & $421(82.7)$ & 0.008 \\
\hline & Yes & $9(40.9)$ & $54(14.6)$ & $13(20.3)$ & $12(22.6)$ & $88(17.3)$ & \\
\hline \multirow[t]{4}{*}{ Bad dreams made wake up } & Once & $5(22.7)$ & $56(15.1)$ & $6(9.4)$ & $7(13.2)$ & $74(14.5)$ & 0.001 \\
\hline & A few time & $0(0.0)$ & $55(14.9)$ & $6(9.4)$ & $2(3.8)$ & $63(12.4)$ & \\
\hline & Frequently & $2(9.1)$ & $140(37.8)$ & $25(39.1)$ & $17(32.1)$ & $184(36.1)$ & \\
\hline & Not at all & $15(68.2)$ & $119(32.2)$ & $27(42.2)$ & $27(50.9)$ & $188(36.9)$ & \\
\hline \multirow[t]{2}{*}{ More interaction with family than usual time } & No & $19(86.4)$ & $306(82.7)$ & $60(93.8)$ & $39(73.6)$ & $424(83.3)$ & 0.031 \\
\hline & Yes & $3(13.6)$ & $64(17.3)$ & $4(6.3)$ & $14(26.4)$ & $85(16.7)$ & \\
\hline \multirow[t]{2}{*}{ Participation in household chores } & No & $22(100)$ & $327(88.4)$ & $56(87.5)$ & $40(75.5)$ & $445(87.4)$ & 0.016 \\
\hline & Yes & $0(0.0)$ & 43(11.6) & $8(12.5)$ & $13(24.5)$ & $64(12.6)$ & \\
\hline \multirow[t]{2}{*}{ Feeling bore at staying home } & Yes & $12(54.50)$ & $302(81.60)$ & $46(71.90)$ & $37(69.80)$ & $397(78.0)$ & 0.004 \\
\hline & No & $10(45.50)$ & $68(18.40)$ & $18(28.10)$ & $16(30.20)$ & $112(22.0)$ & \\
\hline
\end{tabular}

that the model fit is good for data, and it is assumed that this model is correct. The results also indicate that students' information affected activities during the pandemic. Thinking related to COVID-19 affects students activities, and activities during the pandemic affect the mental health of students. Figure 1 and Table 5 illustrate the results.

\section{Discussion}

Students are indispensable for the betterment of any country. Similar to other countries, the Bangladesh government also declared a lockdown to help prevent students from being infected with COVID-19. Though this decision has been taken to ensure the health and safety of the students, the continuous lockdown has led some of them to mental disaster gradually. An online questionnaire-based survey was performed to assess the psychological state of university students of Bangladesh during this lockdown period.

A large portion of the students were from urban areas, most of them were males and aged between 18 to 28 (Table 1). In this study, the student's mental health numbers were categorized into four groups: severe, moderately severe, moderate, and mild. Of which, $10.41 \%$ of them had severe, $12.57 \%$ of them had moderately severe, $72.7 \%$ of them had moderate, and $4.32 \%$ of them had a mild mental disorder (Table 2).
Duration of staying home during this lockdown period, concerned about studies and future career, managing of social media, wasting more time on social media, sleeping time in general, awakened by bad dreams, communication with family members, and assistance with household chores were significantly $(p<0.05)$ connected variables with student's mental health problems (Table 3 ).

The result of the research designated that university students' mental health status regarding the pandemic situation was associated with the age of the students. Students who live in urban areas compared to those who live in rural areas suffer more stress. This situation occurs because of the strong maintenance of this deadly pandemic in urban rather than rural areas. The pandemic situation has produced much skepticism among the students. Students all across the world have suffered because of the COVID-19 pandemic. Studies have shown that undergraduate students were suffering from mental health stress during the COVID-19 pandemic (Kecojevic et al. 2020). Pupils were anxious about their ultimate career, and the result recommended broadly that students were extremely concerned about not being able to arrange work because of the limitation of age restrictions of Bangladesh (Table 3). Students were also troubled about this endless lockdown due to COVID-19 influencing their legitimate education negatively, and eliminating the opportunity of promotion and profession as well (Lipi 2020). 
Table 4 Ordinal logistic regression analysis of factors influencing university student's mental health problems

\begin{tabular}{|c|c|c|c|c|c|c|}
\hline Variables & Categories & Frequency $(n)$ & SE & OR & $p$ value & $\mathrm{OR}(95 \% \mathrm{CI})$ \\
\hline \multirow[t]{4}{*}{ Age } & $18-22$ & 229 & 0.579 & 0.575 & 0.448 & $(-1.57, .70)$ \\
\hline & $23-25$ & 198 & 0.583 & 0.295 & 0.587 & $(-1.46, .83)$ \\
\hline & $26-28$ & 65 & 0.625 & 0.010 & 0.918 & $(-1.16,1.29)$ \\
\hline & More than $28^{*}$ & 17 & - & - & - & - \\
\hline \multirow[t]{2}{*}{ Feeling bore at staying home } & Yes & 397 & 0.252 & 0.001 & 0.971 & $(-0.494,0.512)$ \\
\hline & No* & 112 & - & - & - & - \\
\hline \multirow[t]{2}{*}{ Worried about studies } & Yes & 397 & 0.299 & 3.866 & 0.045 & $(-1.118,-0.02)$ \\
\hline & No* & 112 & - & - & - & - \\
\hline \multirow[t]{2}{*}{ Worried about future career } & Yes & 414 & 0.319 & 0.000 & 0.996 & $(-0.63,0.63)$ \\
\hline & No* & 95 & - & - & - & - \\
\hline \multirow[t]{2}{*}{ Spending more time on social media } & Yes & 421 & 0.294 & 0.850 & 0.356 & $(-0.31,0.85)$ \\
\hline & No* & 88 & - & - & - & - \\
\hline \multirow[t]{4}{*}{ Sleeping time in general } & Before $10 \mathrm{PM}$ & 141 & 0.230 & 8.788 & 0.003 & $(0.231,1.14)$ \\
\hline & Within 10-11 PM & 14 & 0.582 & 4.666 & 0.031 & $(0.115,2.39)$ \\
\hline & Within 11-12 PM & 16 & 0.663 & 1.376 & 0.023 & $(-2.68,0.52)$ \\
\hline & More than $12 \mathrm{AM}^{*}$ & 338 & - & - & - & - \\
\hline \multirow[t]{2}{*}{ More interaction in this quarantine with family } & Yes & 424 & 0.300 & 0.528 & 0.468 & $(0 .-37,0.81)$ \\
\hline & No* & 85 & - & - & - & - \\
\hline \multirow[t]{2}{*}{ Participation in household chores } & Yes & 445 & 0.304 & 8.405 & 0.004 & $(-1.48,-0.29)$ \\
\hline & No* & 64 & - & - & - & - \\
\hline \multirow{4}{*}{$\begin{array}{l}\text { There are many more people diagnosed with coronavirus in } \\
\text { Bangladesh and worldwide than what is being shown }\end{array}$} & Strongly disagree & 50 & 0.373 & 5.558 & 0.018 & $(-0.15,1.61)$ \\
\hline & Disagree & 52 & 0.369 & 1.385 & 0.239 & $(-0.29,1.16)$ \\
\hline & Neither agree nor disagree & 104 & 0.279 & 0.226 & 0.634 & $(-0.42,0.68)$ \\
\hline & Agree* & 33 & - & - & - & - \\
\hline
\end{tabular}

$S E$ Standard error, $O R$ Odds ratio, $C I$ Confidence interval

* reference group

Students using social sites frequently in a day caused higher mental problems compared to those who used sites once or twice a day (Table 3). Students who were able to sleep well were more likely to subdue the psychological health status concerning sleeping late. There is a general relationship between anxiety and sleep disturbances, which plays an enormous role during this pandemic situation, as people think more about job self-doubt and losing people around them (Akundi 2020). Students who participated in household chores felt less mental health problems compared to those who did not participate (Table 3). The sharing of household duties was also supportive of overcoming the mental health problems of students. A survey was conducted of 1060 parents in different-sex couples, and the results show the portion

Table 5 Covariates among latent variables in the structural model

\begin{tabular}{llllll}
\hline Relationship & & & Estimate & S.E. & $p$ value \\
\hline Information & $<->$ & Thinking & 0.036 & 0.018 & 0.047 \\
Information & $<-\rightarrow$ & Activities & -0.145 & 0.010 & $<0.001$ \\
Information & $<-\rightarrow$ & Mental & 0.005 & 0.008 & 0.007 \\
Thinking & $<->$ & Activities & -1.689 & 0.004 & $<0.001$ \\
Thinking & $<->$ & Mental & 0.008 & 0.006 & 0.107 \\
Activities & $<-\rightarrow$ & Mental & 1.145 & 0.004 & $<0.001$ \\
\hline
\end{tabular}

of people sharing household weight equally since the outset of this pandemic (Ebbert 2020). This result also indicated that more communication with family members had a positive impact on the mental health of students (Table 3). The investigation proposed that pandemic situations make connections stronger with family and friends; $60 \%$ of personalities had a higher level of caring in pandemic situations than regular times (Liu 2020). The results showed that students who wake up from sleep several times felt higher mental health problems compared to others (Table 3). A study suggested that students more often found an increase in bed time hour, sleep latency, and wake-up time between before and during the COVID-19 emergency and a worsening of sleep quality and of insomnia symptoms (Marelli et al. 2020).

Ordinal logistic regression analysis recommended that students worried about their studies during this pandemic situation, in contrast to not worried, was favorable to decrease the mental stresses of University students $(p<0.05)$ (Table 4$)$. This result suggested extensively that students were extremely concerned about not obtaining a job because of the restriction of age barriers in Bangladesh. Students also worried about this continuous lockdown due to COVID-19 impacting their regular studies negatively; reducing the option of improving their career as well (Lipi 2020). An early sleeping schedule was also conducive to reduce the psychological health status in respect to sleeping late $(p<0.05)$. There is a common 
Fig. 1 Students mental health path diagram of CFA representing the factor structure

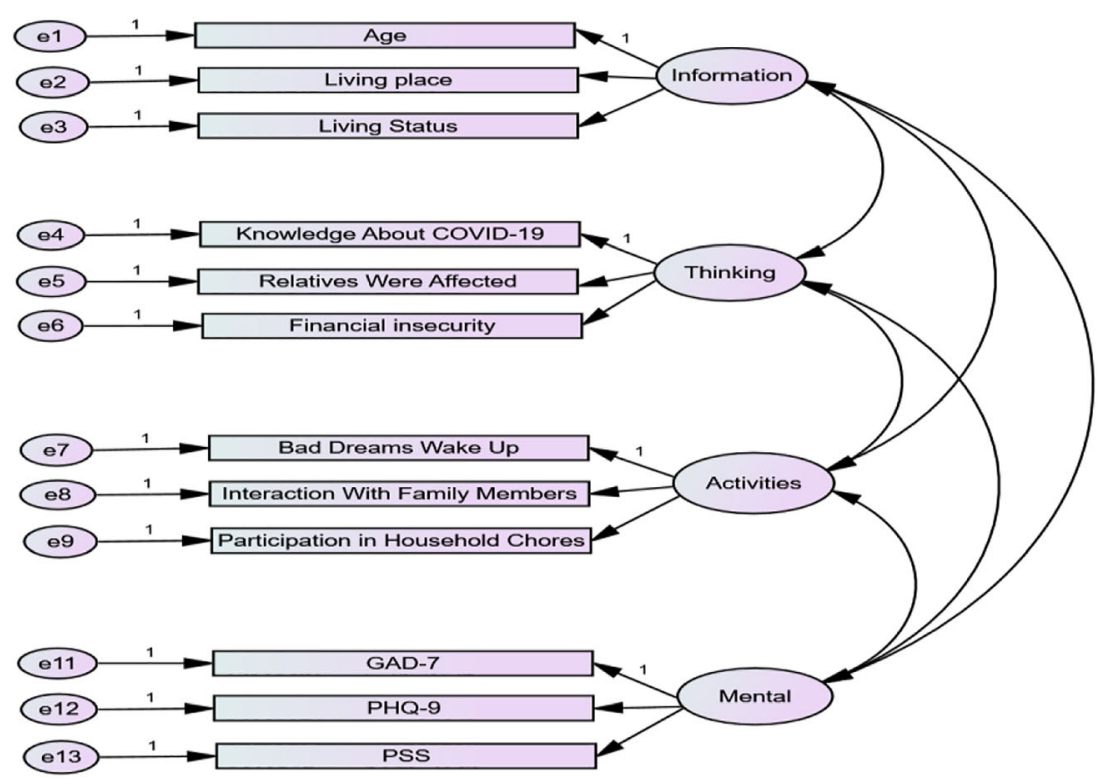

relationship among anxiety and sleep disturbances, which plays a tremendous role during this pandemic situation, because people are thinking more about job insecurity and losing people around them (Akundi 2020). The participation of household chores was also supportive for reducing the mental health problem of students, in respect to not participating $(p<$ 0.05). A survey was conducted of 1060 parents in different sex couples, and the result showed the percentage of people sharing household burdens equally since the outset of this pandemic (Ebbert 2020).

This research indicates that students undergo mostly physiological culmination, and it is recommended that steps should be taken to accomplish mutually settling the difficulty of students as well as contributing physiological well-being services to the university students of Bangladesh. Most of the students seemed unusually stressed concerning their eventual career and education because there is an age limitation for obtaining a government job. The Government and policymakers should take significant actions to minimize mental health problems in university students in Bangladesh.

\section{Limitations}

There are some limitations to our research. First, it was impossible to conduct face-to-face interaction with participants, and this study did not conduct the efficacy of mental services as a cross-sectional study. Although this research gives a cross-sectional study of the psychological disturbances of children, the time frame was short and further research is needed to assess the mental health conditions of university students. Finally, a large sample size is needed to underpin the results.
Acknowledgments We would like to express our gratitude to all the respondents who willingly gave their valuable time, carefully acknowledged and provided straightforward and attentive responses all through the discomfited COVID-19 pandemic. We are also grateful to the people who supported completion and collection of data online.

Authors contribution Muhammad Khairul Alam: Conceptualization, formal analysis, writing - original draft; Ferdous Bin Ali: Conceptualization, writing - original draft; Rajon Banik: Conceptualization, writing - original draft; Sabina Yasmin: Conceptualization, writing - original draft; Nahid Salma: conceptualization, supervision, writing - review \& editing.

Funding This research did not receive any specific grant from funding agencies in the public, commercial, or not-for-profit sectors.

Availability of data and material Data will be made available on request.

Code availability Code will be made available on request.

\section{Declarations}

Conflict of interest The authors declare that they have no known conflicts of interest or personal relationships that could have appeared to influence the work reported in this paper.

Ethical approval Primary datasets were used in this research, and the respondents were given no financial motivation, and anonymity was attested to secure data confidentiality and authenticity. It was also reported that at any time, respondents could be eliminated from the survey without giving any clarification. The respondents also provide their approval for announcing the interpreted results of this study without their identifiable information. This research was provided online in full conventionality with the prerequisites of the Helsinki Declaration on human participant's research.

Consent to participate All the participants willingly participated by giving their consent. The formal consent was taken from each respondent before completing the questionnaire. 
Consent for publication Authors give permission for publications. Authors are responsible for correctness of the statements provided in the manuscript.

\section{References}

Akundi S (2020) Losing sleep over the coronavirus pandemic? In: The Hindu. https:/www.thehindu.com/sci-tech/health/how-the-covid19-lockdown-is-changing-our-sleep-cycle/article31432402.ece. Accessed 7 Jun 2020

Anderson RM, Heesterbeek H, Klinkenberg D, Hollingsworth TD (2020) How will country-based mitigation measures influence the course of the COVID-19 epidemic? Lancet 395:931-934. https://doi.org/10. 1016/S0140-6736(20)30567-5

Banik R, Rahman M, Sikder MT, Gozal D (2020) COVID-19 in Bangladesh: public awareness and insufficient health facilities remain key challenges. Public Health 183:50-51. https://doi.org/10. 1016/j.puhe.2020.04.037

Brooks SK, Webster RK, Smith LE et al (2020) The psychological impact of quarantine and how to reduce it: rapid review of the evidence. Lancet 395:912-920. https://doi.org/10.1016/S0140-6736(20) 30460-8

Budikayanti A, Larasari A, Malik K et al (2019) Screening of generalized anxiety disorder in patients with epilepsy: using a valid and reliable Indonesian version of generalized anxiety Disorder-7 (GAD-7). Neurol Res Int. https://doi.org/10.1155/2019/5902610

Cohen S, Kessler RC, Gordon LU (1994) Measuring stress: a guide for health and social scientists. Oxford University Press

Ebbert S (2020) Men are taking on (slightly) more household chores during pandemic. In: Boston Globe. https://www.bostonglobe. com/2020/05/21/metro/pandemic-silver-lining-men-taking-slightlymore-household-chores/. Accessed 7 Jun 2020

Goothy SSK, Goothy S, Chakraborty H (2020) COVID-19 lockdown impact on the mental health of students: need to start a mental health cell. 7:51-52. https://doi.org/10.15406/mojap.2020.07.00289

Hu L, Bentler PM, Hu L (1999) Cutoff criteria for fit indexes in covariance structure analysis : conventional criteria versus new alternatives cutoff criteria for fit indexes in covariance structure analysis : conventional criteria versus new alternatives. Struct Equ Model A Multidiscip J 6:1-55. https://doi.org/10.1080/10705519909540118

Institute of Epidemiology Disease Control and Research (2020) Covid-19 status for Bangladesh. https://www.iedcr.gov.bd/. Accessed 4 Aug 2020

Kecojevic A, Basch CH, Sullivan M, Davi NK (2020) The impact of the COVID-19 epidemic on mental health of undergraduate students in New Jersey, cross-sectional study. PLoS One 15:1-16. https://doi. org/10.1371/journal.pone.0239696
Kroenke K, Spitzer RL, Williams JBW (2001) The PHQ-9.Pdf. J Gen Intern Med 16:606-613. https://doi.org/10.1046/j.1525-1497.2001. 016009606.x

Lipi S (2020) Students fear about failing, missing jobs in lockdown. In: bdnews24.com. https://bdnews24.com/education/2020/04/22/ students-fear-about-failing-missing-jobs-in-lockdown. Accessed 7 Jun 2020

Liu Y-L (2020) Is Covid-19 changing our relationships? In: BBC. https:// www.bbc.com/future/article/20200601-how-is-covid-19-isaffecting-relationships

Marelli S, Castelnuovo A, Somma A et al (2020) Impact of COVID-19 lockdown on sleep quality in university students and administration staff. J Neurol 268:8-15. https://doi.org/10.1007/s00415-02010056-6

Rubin GJ, Wessely S (2020) The psychological effects of quarantining a city. BMJ 368:1-2. https://doi.org/10.1136/bmj.m313

The Daily star (2020) Coronavirus scare : all educational institutions closed till march 31. In: Dly. star. https://www.thedailystar.net/ backpage/news/coronavirus-scare-all-educational-institutions-shuttill-march-31-1881658. Accessed 30 May 2020

Wang C, Horby PW, Hayden FG, Gao GF (2020a) A novel coronavirus outbreak of global health concern. Lancet 395:470-473. https://doi. org/10.1016/S0140-6736(20)30185-9

Wang C, Pan R, Wan X, et al (2020b) Immediate psychological responses and associated factors during the initial stage of the 2019 coronavirus disease (COVID-19) epidemic among the general population in China. Int J Environ Res Public Health 17. https://doi.org/10.3390/ ijerph17051729

World Health Organization (2020a) WHO Director-General's opening remarks at the media briefing on COVID-19 - 11 March 2020. https://www.who.int/dg/speeches/detail/who-director-general-sopening-remarks-at-the-media-briefing-on-covid-19\%2D\%2D-11march-2020. Accessed 23 May 2020

World Health Organization (2020b) Coronavirus disease (COVID-2019): situation report, 6. WHO, Bangladesh

Xiang YT, Yang Y, Li W et al (2020) Timely mental health care for the 2019 novel coronavirus outbreak is urgently needed. Lancet Psychiatry 7:228-229. https://doi.org/10.1016/S2215-0366(20) 30046-8

Xiao C (2020) A novel approach of consultation on 2019 novel coronavirus (COVID-19)-related psychological and mental problems: structured letter therapy. Psychiatry Investig 17:175-176. https:// doi.org/10.30773/pi.2020.0047

Zandifar A, Badrfam R (2020) Iranian mental health during the COVID19 epidemic. Asian J Psychiatr 51:101990. https://doi.org/10.1016/j. ajp.2020.101990

Publisher's note Springer Nature remains neutral with regard to jurisdictional claims in published maps and institutional affiliations. 